\title{
Development of mathematical model for hydraulic fracturing design
}

\author{
Muhammad Aslam Md Yusof • Nur Adilla Mahadzir
}

Received: 11 February 2014/ Accepted: 22 May 2014/Published online: 12 July 2014

(c) The Author(s) 2014. This article is published with open access at Springerlink.com

\begin{abstract}
Hydraulic fracturing has been proposed as one of the stimulation techniques to economically increase oil and gas production. The design of hydraulic fracturing must make allowances for various considerations, parameters, and complicated calculations. Therefore, this paper presents a simple and fast mathematical model for hydraulic fracturing design treatment. The objective of this project was to develop a mathematical model for hydraulic fracturing design and run case studies for model verification and validation. Mathematical model for hydraulic fracturing design was coded. The code has been verified using several case studies with pronounced rate of success. Verification of mathematical model for hydraulic fracturing design has established a slight percentage differences between the calculated values in the model and manual hand calculation while mathematical model validation have established a very small percentage differences between the calculated values and the field data values. In conclusion, this project will be able to predict the optimization of hydraulic fracturing before conducting any hydraulic fracturing stimulation for the well in the field.
\end{abstract}

Keywords Hydraulic fracturing design - Mathematical model $\cdot$ Simulation technique

M. A. Md Yusof $(\bowtie) \cdot$ N. A. Mahadzir

Universiti Teknologi PETRONAS, Tronoh, Malaysia

e-mail: aslam.myusof@petronas.com.my

N. A. Mahadzir

e-mail: adilla.mahadzir@gmail.com

\author{
List of symbols \\ $k \quad$ Permeability \\ $\Delta P \quad$ Differential treating pressure \\ $\varnothing \quad$ Porosity \\ $\varnothing_{\text {sand }} \quad$ Porosity of sand \\ $\rho_{\text {sand }} \quad$ Sand density \\ $\mu \quad$ Viscosity \\ C Fracturing fluid coefficient \\ $d_{\mathrm{e}} \quad$ Diameter of circular pipe \\ $m \quad$ Slope of fluid loss curve \\ $A_{f} \quad$ Area of filter paper \\ $q_{t} \quad$ Barrels of fluid per minute \\ $W \quad$ Fracture width \\ Eff Fracture efficiency \\ $\operatorname{erfc}(x) \quad$ Complementary error function of $x$ \\ $\mathrm{H}_{\mathrm{h}} \quad$ Hydraulic horsepower \\ $P_{s} \quad$ Surface injection pressure \\ $\Delta P_{s} \quad$ Hydrostatic pressure \\ $\Delta P_{\text {perf }}$ Pressure drop across through perforation in \\ equation $P_{s}=P_{t}+\Delta P_{\text {perf }}-\Delta P_{s}$ \\ $\Delta P_{f} \quad$ Frictional pressure drop in pipe \\ $P_{t} \quad$ Bottom hole fracture treating pressure \\ PR Productivity ratio \\ $h \quad$ Formation thickness \\ $r_{\mathrm{e}} \quad$ Drainage radius \\ $r_{\mathrm{w}} \quad$ Wellbore radius \\ LEC Line efficiency correlation \\ HF Hydraulic fracturing \\ $G_{\mathrm{f}} \quad$ Fracture gradient \\ D Depth \\ $t \quad$ Injection time \\ $v \quad$ Average flow velocity in pipe \\ $S \quad$ Weight of sand \\ $V \quad$ Volume per unit area of fracture \\ $X \quad$ Sand concentration
}




$\begin{array}{ll}A(t) & \text { Area of one face of the fracture at time } t \\ q_{i} & \text { Injection rate } \\ x & \frac{2 C \sqrt{\pi} t}{W} \\ C_{f} & \text { Compressibility coefficient }\end{array}$

\section{Introduction}

Hydraulic fracturing is a well stimulation technique that has been employed in the oil and gas industry since 1947 (API 2009). According to Association of American State Geologists (2012), hydraulic fracturing or known as "fracking", "hydrofracking" or "fracing" as applied in oil and gas industry is the process of pumping a mixture of water, sand and other chemical additives under high pressure to create fractures originating from the wellbore in a producing formation to provide increased flow channels for production. A viscous fluid containing a proppant such as sand is injected under high pressure until the desired fracturing is achieved. The pressure is then released allowing the fluid to return to the well. The proppant, however, remains in the fractures preventing them from closing. Hydraulic fracturing is usually useful to increase productivity index (PI) of the well especially in low permeability reservoir and increase the flow rate of oil and/or gas from wells that have been damaged. Damage occurs because drilling and/or completion fluids leak into the reservoir and plug up the void spaces and pore throats. Then, the permeability is reduced because the pores have been plugged and the fluid flow in this damaged portion of the reservoir may be substantially reduced. To stimulate a damaged reservoir, a short, conductive hydraulic fracture is often the desired solution.

Thousands of treatments are implemented each year in a wide range of geological formations which may vary from low permeability gas fields, weakly consolidated offshore sediments, soft coal beds for methane extraction, naturally fractured reservoirs, and geometrically complex structures (Adachi et al. 2007). Thus, it is very important to study hydraulic fracturing design before conducting any hydraulic fracturing stimulation treatment for the well. A successful hydraulic fracturing stimulation treatment is dependent on many factors. Its design requires a number of considerations such as the prediction of well productivity for various fracture lengths and conductivities, parametric studies on fracture geometry requirement for particular types of formations, selection of appropriate types of fracture materials and determination of fracture design criteria.

Hydraulic fracturing design models are used today as a prediction tool for the optimization of hydraulic fracturing. In this study, since there are many parameters needed to be calculated for the design on hydraulic fracturing, a mathematical model has to be developed.
In this project, a research study of hydraulic fracturing has been carried out to investigate the parameters needed to be calculated for hydraulic fracturing design. An alternative method to estimate hydraulic fracturing design parameters has been presented by developing a mathematical model using Microsoft Excel Visual Basic for Applications (VBA). Applicability and validity of the model is then demonstrated using field data and results.

\section{Hydraulic fracturing design}

Ali Daneshy (2010) points out that engineering computation always precede a fracturing treatment which comprises of the calculation of fluid volume and viscosity, injection rate, weight of proppant, volumes of different phases of the job (pre-pad, pad, slurry, and displacement), surface and bottom hole injection pressure, hydraulic horsepower required at the surface, and the mechanical equipment needed for this.

According to Jabbari and Zeng (2012), the best hydraulic fracturing design depends very much on the environment in which the fracture treatment will be carried out. The characteristics that define the environment are controllable parameters, such as wellbore casing, tubing and wellhead configurations, wellbore downhole equipment, lateral length, well spacing, perforation location and quantity, fracturing fluid and proppant characteristics, and fracturing treatment rate and pumping schedule.

Veatch (1983) mentioned on the general treatment design consideration which limited to selecting the appropriate types of materials (e.g., fluids, additives, and proppants), the appropriate volumes of materials, injection rates for pumping these materials, and the schedule for injecting the materials.

\section{Basis/assumptions}

In this model, injection rate and time of injection are assumed based on the previous fracture jobs in the area. From these assumptions, it is possible to obtain the surface pressure, horsepower requirements, maximum quantity of propping agent needed and also the productivity ratio.

\section{Fracture extent}

In API (2009), the fracture extents are divided into two which consists of horizontal fracture and vertical fracture The fracture plane in productive layer is assumed to be vertical when the fracture gradient is $0.7 \mathrm{psi} / \mathrm{ft}$ of $2,000 \mathrm{ft}$ depth or less, and horizontal when the fracture gradient is $1.0 \mathrm{psi} / \mathrm{ft}$ of $2,000 \mathrm{ft}$ depth or greater. 
Productivity ratios

For the productivity ratio, it is impossible to predict exactly the productivity ratio of the well, owing to the fact that every fracture pattern is different and unique. However, it is possible to estimate the productivity ratios for vertical and horizontal fractures if the radial pattern of fracture is assumed as uniform. For the case of horizontal fracture, productivity ratio equation can be obtained provided it is assumed that there is zero vertical permeability in the fracture zone.

Fracture area

$A(t)=\frac{q_{i} W}{4 \pi C^{2}}\left[e^{x^{2}} \operatorname{erfc}(x)+\frac{2 x}{\sqrt{\pi}}-1\right]$

An expression of fracture area at any time may be derived using the assumption of:

1. The fracture has uniform width, the flow of fracture fluid into formation is linear and the direction of flow is perpendicular to the fracture

2. The velocity of flow into the formation at any point on the fracture face is a function of the time of exposure of the point to flow

3. The velocity function $v=f(t)$ is the same for every point in the formation, but the zero time for any point is defined as the instant that fracturing fluid first reaches it

4. The pressure in the fracture is equal to the sandface injection pressure, which is constant.

Fracturing fluid

Howard and Fast (1957) stated that since the fracturing fluid properties are reflected through the fracturing fluid coefficient, $C$, it is important to establish a method for the determination of this factor for various types of fracturing fluids. The fracturing fluid coefficient, $C$, defines the three types of linear flow mechanisms countered with fracturing fluids for which comprises of:

Viscosity controlled fluids Viscous or semi-viscous fracture fluids in situations where the viscosity controls the amount of fluid loss taking place during fracturing. Therefore, the viscosity of the fracture fluid controls the amount of fluid loss to the formation. Thus, for this case, the fracturing fluid coefficient, $C_{v}$ is defined as:
$C_{v}=0.0469\left(\frac{k \Delta P \varnothing}{\mu}\right)^{1 / 2} \mathrm{ft} / \sqrt{\min }$

Reservoir controlled fluid This category of fracturing fluids has low viscosity and high fluid loss characteristics in which the physical properties are identical to those of the reservoir fluid (Craft et al. 1962). The fracturing fluid coefficient, $C_{c}$ is:

$C_{c}=0.374 \Delta P\left(\frac{k c_{f} \varnothing}{\mu}\right)^{1 / 2} \mathrm{ft} / \sqrt{\min }$

Wall-building fluids These fluids build a temporary filter cake or wall on the face of the fracture as it is exposed. The fracturing fluid coefficient for wall-building fluid, $C_{w}$ is represented below:

$C_{w}=\frac{0.0164 m}{A_{f}} \mathrm{ft} / \sqrt{\min }$

\section{Model development, verification and validation}

Model development

Model verification and validation are essential parts of the model development process if models to be accepted and used to support decision making (Charles 2005). Five case studies were conducted for verification and validation of mathematical model. The project focused on the calculation of hydraulic fracturing design parameters in vertical and horizontal fracture. Figure 1 shows the calculation procedures for both fracture orientations.

Case 1 Well A depth is at 7,000 ft and was treated via 4.892 in casing and 2 in tubing. Since the well depth is at $7,000 \mathrm{ft}$, the fracture extent of the well is assumed as vertical with the fracture gradient of $0.7 \mathrm{ft} / \mathrm{psi}$. The resulted field data show that the fracture was treated using $151,000 \mathrm{lb}$ of maximum weight of sand, with 37,800 gal of fracture fluid volume. The surface injection pressure used was 3,129 psi whereby the hydraulic pump was operated at 2,338 hp. The productivity ratio (PR) obtained after fracture treatment was 6.5.

Case 2 The well B was drilled at depth $10,000 \mathrm{ft}$ with the fracture gradient of $0.64 \mathrm{ft} / \mathrm{psi}$ and assumed to be in vertical fracture extent. Based on available field data, it shows that the fracture was treated using 420,000 lb of maximum weight of sand, with 100,000 gal of fracture fluid volume. 2,500 psi injection pressure at the surface was used whereby the hydraulic pump operated at 
Fig. 1 Calculation procedures for hydraulic fracturing design for vertical and horizontal fractures

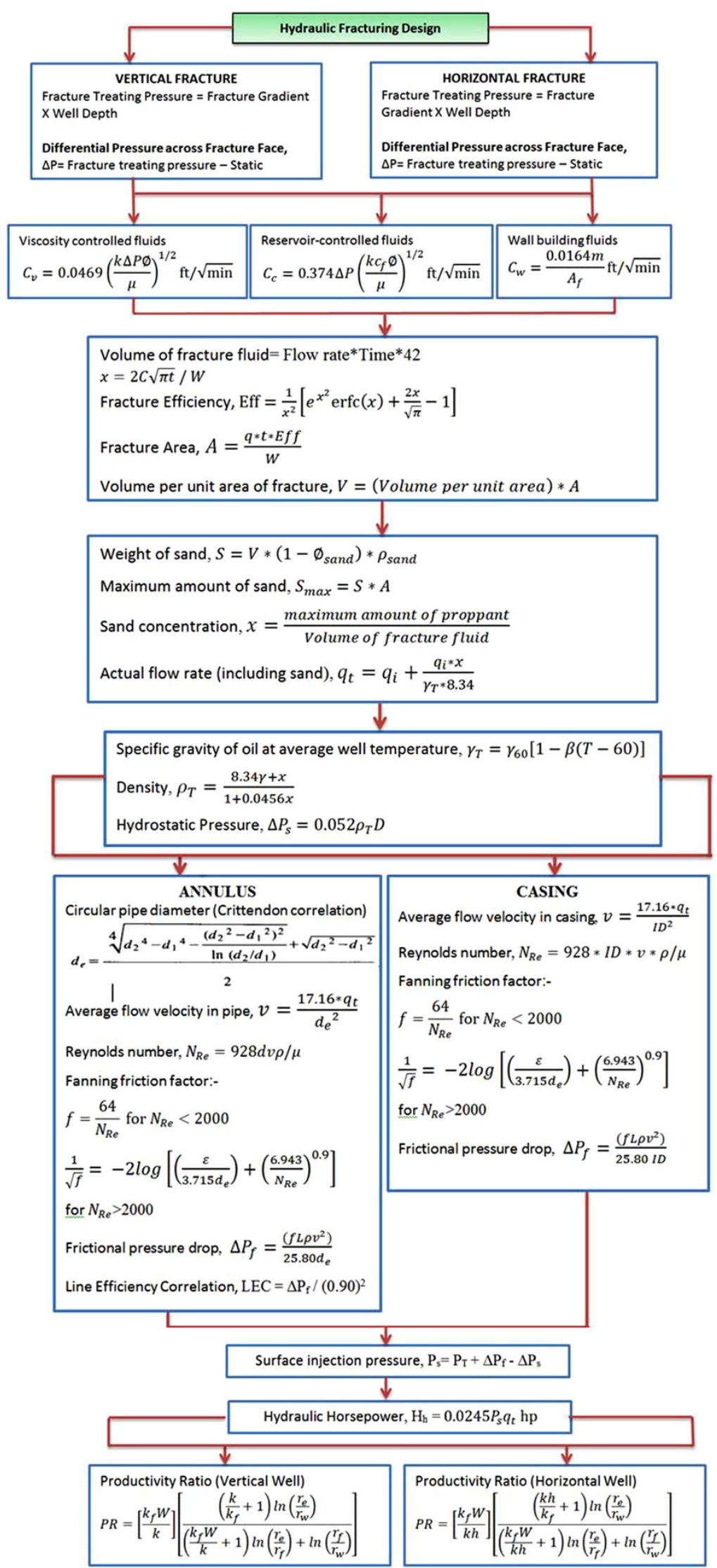


2,300 hp. The result shows that PR after fracture treatment was 9.

Case 3 The well $\mathrm{C}$ was assumed horizontal as the depth of the well is $2,000 \mathrm{ft}$ with a fracture gradient of $1 \mathrm{psi} / \mathrm{ft}$. Since the fracturing fluid has low viscosity of $4 \mathrm{cp}$, the fracture fluid type is characterized in reservoir controlled fluid. The resulted field data indicated that the maximum amount of sand needed for fracturing was 176,600 lb with the fracture fluid volume of 40,000 gal. The injection pressure was at 3,263 psi and the hydraulic horsepower used was $2,886 \mathrm{hp}$. The PR of the well after fracturing was 5.

Case 4 The type of fracture extent is vertical as the well was drilled up to $6,500 \mathrm{ft}$ with the fracture gradient of $0.68 \mathrm{psi} / \mathrm{ft}$. The resulted data showed the value of 6.4 for productivity ratio after fracture treatment. 226,700 gal of fracture fluid was treated at 3,550 psi of injection pressure and 2,670 hp of hydraulic horsepower. 400,000 gal maximum amount of sand was needed for the success of the treatment.

Case 5 The well is at depth of 1,600 ft with a fracture gradient of $1 \mathrm{psi} / \mathrm{ft}$. The resulted $\mathrm{HF}$ for the field used $462,000 \mathrm{lb}$ of amount of sand and 84,000 gal of volume of fracture fluid. The well was injected at 2,500 psi and PR after fracturing was at the value of 7.4.

The hydraulic fracturing design coding was done for two different types of fracture extent namely vertical fracture and horizontal fracture. The type of fracture establishes the directional permeability of the formation to be used in calculating the fluid loss during fracturing as well as productivity ratio of the fractured wells. In addition, the type of fracture determines the advisability of using diverting agents.

In the coding of vertical and horizontal fractures, three different types of fracture fluids have been coded in the system which are viscosity controlled fluids, reservoir controlled fluids and wall-building fluids. Viscosity controlled fluids comprise of viscous or semi-viscous fracture fluids; reservoir controlled fluids consist of fracturing fluids with low viscosity and high fluid loss characteristic, while wall-building fluids build a temporary filter cake. The user can select either viscosity controlled fluids, reservoir controlled fluids or wall-building fluids as the fracture fluids type to be used.

After the amount of sand, hydrostatic pressure drop and volume of fracturing fluid has been calculated, the procedure on the method of fracturing was coded in VBA. The fracture is done either through casing or annulus. In fracture through annulus, the diameter of circular pipe is calculated using the Crittendon's correlation which has been coded in the window. The diameter then is used to calculate the average velocity, Reynolds number, frictional pressure drop as well as hydraulic horsepower. For fracture through casing, the internal diameter of the casing is used for the calculations of average velocity, Reynolds number, frictional pressure drop as well as hydraulic horsepower. Lastly, the equation of productivity ratio has been coded in VBA.

\section{Verification}

Verification is done to ensure that the model is programmed suitably, the algorithms have been implemented accurately and the model does not contain error, oversights or bugs. The verification of coding has been tested to determine whether the coding will successfully run without any errors. The results of manual calculations and the mathematical model of hydraulic fracturing are then compared and the percentage differences have been calculated.

From the results, it shows that the minimum percentage difference obtained between VBA coding and manual calculations is $0 \%$, while the maximum percentage difference obtained between calculation in VBA coding and manual calculation is $2.63 \%$. Therefore, the results conclude that the coding is free from error and viable for data validity. The coding is tested and validated for all five cases.

\section{Validation}

The results from the mathematical model were compared with the field results for all cases and the percentage differences were calculated. The resulted parameters from the mathematical model and field data were then converted into bar chart to analyze the difference in the values of hydraulic fracturing design parameters for all cases and analyzed the validity of the equations used to calculate the parameters of hydraulic fracturing design.

There are five main parameters that have been considered for comparison namely amount of sand, volume of fracture fluid, surface injection pressure, hydraulic horsepower and productivity ratio. Based on the overall results, the validation has established a range of $0-15 \%$ between the calculated value and case studies values.

The comparison of maximum amount of sand for all cases between the calculated model and field data is presented in Fig. 2.

In Case 1, the percentage difference between the field and calculated values was $1.12 \%$ followed by Case 2 which is $0.31 \%$, Case 3 which is $0.49 \%$, Case 4 which is $5.14 \%$ and Case 5 which is $4.96 \%$. The percentage differences for all values are $<5 \%$. This shows that the equations and correlations used to calculate the maximum amount of sand for hydraulic fracturing design in the mathematical model are valid. 


\section{Maximum amount of sand for each cases}

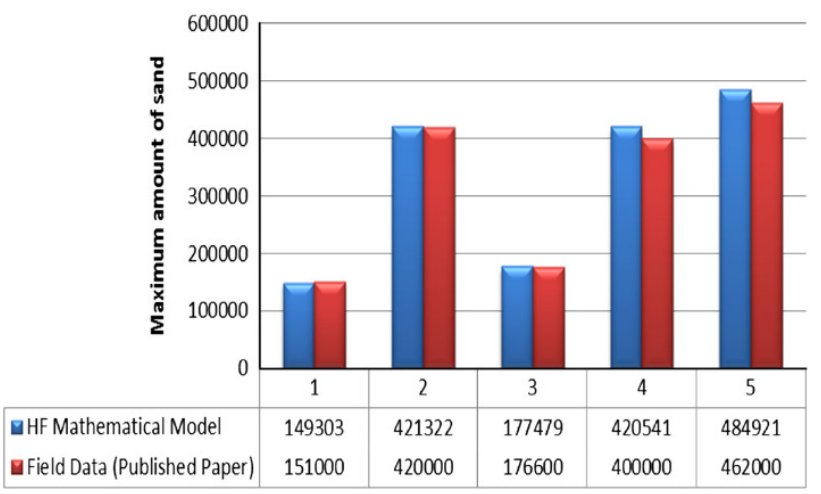

Fig. 2 Graph of maximum amount of sand between HF mathematical model and field data for all cases

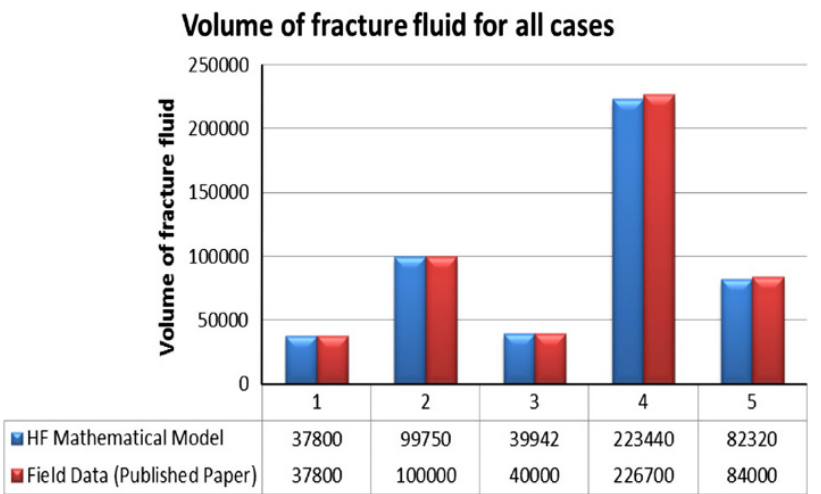

Fig. 3 Graph of volume of fracture fluid between HF mathematical model and field data for all cases

Moreover, for Case 1 (Fig. 3), there are no changes between the field data and calculated volume of fracturing fluid. For the rest of the cases, there are slight differences in the volume of fracture fluid. Case 2 obtained $0.25 \%$ differences, Case 3 obtained the differences of $0.145 \%$, Case 4 for about $1.43 \%$ and last but not least, Case 5 obtained $2 \%$ of percentage differences in the volume of fracture fluid.

To wrap up, the volume of fracture fluid between HF mathematical model and field data for all cases displayed low values of percentage differences which were $<2 \%$.

Therefore, the correlations and equations used to calculate the volume of fracture fluid in mathematical model for hydraulic fracturing design were workable and can be accepted.

In addition, for surface injection pressure (Fig. 4), the percentage difference between the field and calculated values for Case 1 was slightly high; $6.04 \%$. However, the rest of the cases showed high percentage differences. The percentage difference Case 2 was $17.32 \%$, followed by Case 3 which was $14.59 \%$, Case 4 which is $13.38 \%$ and Case 5 which is $14.36 \%$. Hence, it can be concluded that
Surface Injection Pressure for all cases

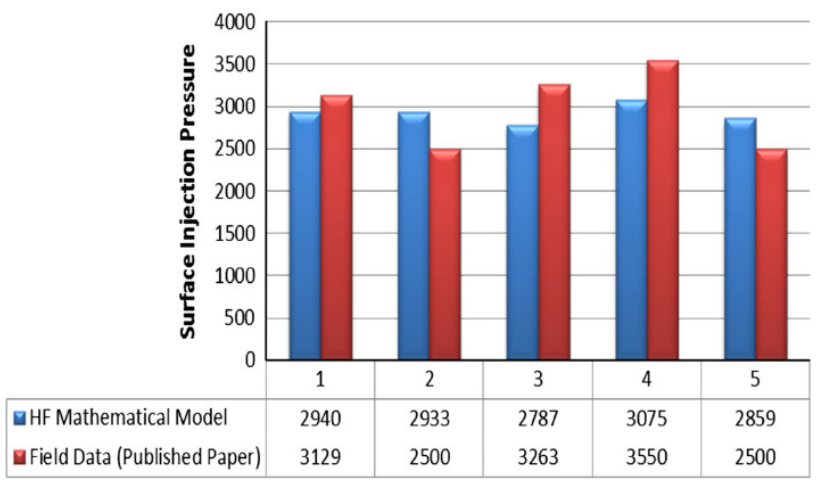

Fig. 4 Graph of surface injection pressure between HF mathematical model and field data for all cases

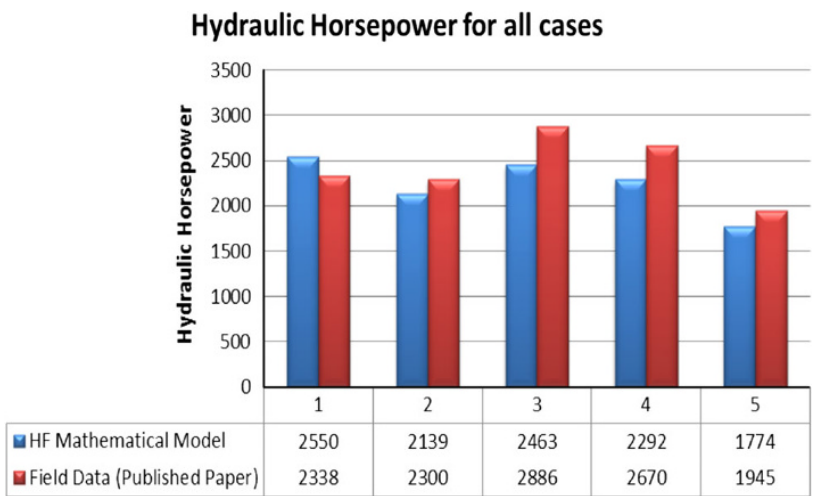

Fig. 5 Graph of hydraulic horsepower between HF mathematical model and field data for all cases

the percentage differences are quite high in the values of surface injection pressure between the calculated model and field data.

Furthermore, the bar chart in Fig. 5 shows the hydraulic horsepower results between hydraulic fracturing mathematical model and field data for all cases.

For Case 1, Case 2 and Case 5, the percentage difference between the field and calculated values is slightly high which are 9.07, 7 and $8.79 \%$, respectively. These values nearly reached $10 \%$ but still can be acceptable. However, the rest of the cases which are Case 3 and Case 4 show high percentage differences. The percentage difference for Case 3 is $14.66 \%$, and Case 4 is $14.16 \%$, which nearly reached $15 \%$.

The comparison of productivity ratio for all cases between the calculated model and field data is presented in Fig. 6. The bar chart shows the productivity ratio results between hydraulic fracturing mathematical model and field data for all cases. For Case 1, the percentage difference is $3.07 \%$ followed by Case 2 which is $7.11 \%$, Case 3 which is $1 \%$, Case 4 which is $2.11 \%$ and Case 5 which is $4.32 \%$. All cases displayed low amount of percentage 


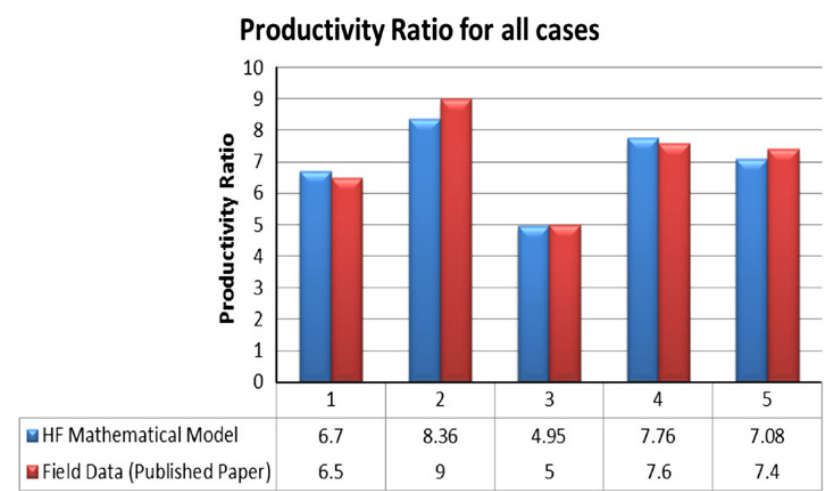

Fig. 6 Graph of productivity ratio between HF mathematical model and field data for all cases

differences except for Case 2 in which the percentage difference reached more than $5 \%$. Therefore, the correlation and equations used to calculate the productivity ratio in mathematical model for hydraulic fracturing design are practical and can be accepted.

\section{Discussion}

The important parameters required for a hydraulic fracturing design such as maximum amount of sand needed, volume of fracture fluid, surface injection pressure, hydraulic horsepower and productivity ratio after fracturing can be predicted prior to fracture treatment. This is very important to determine the effectiveness of the proposed treatment and also can measure the economic feasibility of the treatment project. From the previous result, the maximum amount of sand for all cases showed slight differences (approximately $<5 \%$ ) between the values of $\mathrm{HF}$ mathematical model and field data. The volume of fluid for all cases also showed minimum values of percentage differences (approximately $<2 \%$ ) between the values of $\mathrm{HF}$ mathematical model and field data. The productivity ratio of the well after fracturing also showed the percentage differences which range from 1 to $7 \%$. This shows that the equations used to obtain the values of maximum amount of sand and volume of fracture fluid in HF design are valid, practical and workable.

However, the surface injection pressure shows slightly high values which approximately reach $15 \%$ of percentage differences between calculated values and field values for all cases. This is due to the assumption made in this model in which the pressure drop across perforation was assumed negligible because the values are usually small compared to other pressure terms. Therefore, the surface injection pressure can be obtained from equation
$P_{s}=P_{t}+\Delta P_{\text {perf }}-\Delta P_{s}$

Accounting the values of pressure drop across perforation, it is the reason for slightly high percentage differences in the values of surface injection pressure for several case studies.

From the results too, since the values of percentage differences for surface injection pressure are slightly high, the percentage differences for hydraulic horsepower also show the values reaching $15 \%$. These issues can be analyzed using the equation of

$\mathrm{H}_{\mathrm{h}}=0.0245 \times P_{s} \times q_{t}$

From the equation, to get the value of hydraulic horsepower, surface injection pressure value is required. Therefore, as the percentage difference of surface injection pressure is high, the percentage difference of hydraulic horsepower will be high too.

\section{Conclusion}

This study has clearly demonstrated that the mathematical model for hydraulic fracturing design can be successfully applied to problems facing the petroleum industry. Even though the mathematical model developed is covering a broad problem domain, it still can give good and precise result. For future continuation, another parameter like fracture propagation model and economic analysis can be included as part of the mathematical model to determine the optimization of hydraulic fracturing treatment.

Open Access This article is distributed under the terms of the Creative Commons Attribution License which permits any use, distribution, and reproduction in any medium, provided the original author(s) and the source are credited.

\section{References}

Adachi J, Siebrits E, Peirce A, Desroches J (2007) Computer simulation of hydraulic fractures. Int J Rock Mech Min Sci 44:739-757

API (2009) Hydraulic fracturing operations, well construction and integrity guidelines, NW, Washington DC, pp 15-22

Association of American State Geologists (2012) Hydraulic fracturing. Retrieved from www.stategeologists.org

Charles MM (2005) Model verification and validation, University of Chicago \& Argonne National Laboratory

Craft BC, Graves ED, Holden WR (1962) Hydraulic fracturing: well design drilling and production. Prentice-Hall Inc, New Jersey, p 483

Daneshy A (2010) Hydraulic fracturing to improve production, Daneshy Consultants International

Howard GC, Fast CR (1957) Optimum fluid characteristics for fracture extension. Drilling and Production Practice (API), NY, pp 261-270 
Jabbari H, Zeng Z (2012) Hydraulic fracturing design for horizontal wells in the Bakken formation. Department of Geology and Geological Engineering, University of North Dakota, Grand Forks, USA
Veatch RW (1983) Overview of current hydraulic fracturing design and treatment technology-part 1, part 2. SPE Paper, 10039 (1982), 11922. J Pet Technol 35:677-687, 853-864 